ISSN 2466-2232

Online ISSN 2466-2100

\title{
$\mathrm{Ni}-\mathrm{Cr}-\mathrm{Fe}$ 계 합금의 고온균열: 시험법 및 야금학적 영향
}

\author{
남 상 우,***김 철 희 ·김 영 민,* \\ *한국생산기술연구원 용접접합그룹 \\ **서울대학교 재료공학부
}

\section{Hot Cracking of Ni-Cr-Fe Alloys: Test Methods and Metallurgical Effect}

\author{
Sangwoo Nam*,**, Cheolhee Kim*, and Young-Min Kim*,† \\ *Joining R\&D Group, KITECH, Incheon, 21999, Korea \\ **Dept. of Materials Science and Engineering, Seoul National University, Seoul, 08826, Korea
}

†Corresponding author : ymkim77@kitech.re.kr

(Received September 5, 2017 ; Revised October 11, 2017 ; Accepted October 18, 2017)

\begin{abstract}
$\mathrm{Ni}-\mathrm{Cr}-\mathrm{Fe}$ alloys have excellent corrosion resistance and strength at high-temperature, thus these alloys are used as basic structural materials in high-temperature parts such as aerospace industry, nuclear power generators, and ultra-supercritical power plants. Also, the materials are widely utilized for similar and dissimilar welding of austenitic alloys, however, various hot cracking such as solidification cracking, liquation cracking and ductility-dip cracking occur. Various types of hot cracking test methods have been developed to reproduce the thermal/mechanical deformation of the actual welding, and the evaluation of cracking susceptibility employed this methods was discussed. In this paper, previous studies to understand the mechanisms of crack formation and to reduce hot cracking were introduced. In addition, the effect of the various carbides $\left(\mathrm{MC}, \mathrm{M}_{23} \mathrm{C}_{6}\right)$ and intermetallic compounds ( $\mathrm{\gamma}^{\prime}, \mathrm{\gamma}^{\prime \prime}, \delta, \sigma$ and Laves) caused by solidification and reheating during multi-pass welding and the influence of metallurgical changes on crack sensitivity were described.
\end{abstract}

Key Words : Hot cracking, Ni alloys, Ductility dip cracking, alloy 690, Varestraint test

\section{1. 서 론}

$\mathrm{Ni}-\mathrm{Cr}-\mathrm{Fe}$ 계 합금은 고온 내식성, 내열성, 고온 강도 등 기계적 성질이 우수하여 자동차 산업 및 원자력 및 화력 발전소에서 열교환 부품, 고온 압력용기 등 고온 의 유체가 흐르는 곳에서 주로 쓰이고 있다 ${ }^{1)}$. 또한, 재 료의 개발로 초고온 부품에도 사용이 늘면서 우주항공 산업에도 니켈합금의 중요성이 계속 커지고 있다. 이 합금은 잘 알려진 오스테나이트계 스테인리스강과 같이 면심입방구조의 8 상을 기본으로 하며, 스테인리스보다 높은 $\mathrm{Ni}$ 함량으로 인해서 높은 온도에서 우수한 내구성 을 나타낸다.

이 합금은 다른 원소의 고용한계가 높고 고용강화 등
의 강화기구가 적용되어 다양한 원소들이 합금화 되어 있다. 순금속은 녹는점이 특정온도로 국한되는 반면에, 니켈합금 같은 고합금은 많은 원소가 고용되어 있기 때 문에 응고되는 온도(고상선)와 액화되는 온도(액상선) 가 분리되어 고상과 액상이 공존하는 영역이 존재한다. 이는 응고과정 중에 용질원자의 석출 및 편석을 유발시 키고 균열감수성을 증가시킨다.

합금의 용접부에 나타나는 균열을 생성 온도로 구분 하게 되면 크게 고온균열과 저온균열로 구분되며 저온 균열은 용접부가 $200{ }^{\circ} \mathrm{C}$ 이하의 저온에서 발생하는 균 열로 정의하며 확산성수소의 영향으로 상온에서 일정한 기간이 경과한 후에 발생하는 것을 특징으로 지연균열 이라고도 불린다.

고온균열은 이러한 저온균열과 대비되는 개념으로서

Journal of Welding and Joining, Vol.35 No.5(2017) pp7-15

https://doi.org/10.5781/JWJ.2017.35.5.2 
크게 응고균열(solidification cracking)과 액화균열 (liquation cracking)을 포함하는 편석균열과 연성저 하균열(ductility dip cracking)로 구분할 수 있다. Fig. 1에 보여지듯이 편석균열을 일으키는 온도영역을 brittle temperature range(BTR)이라 하고, 연성저 하균열을 일으키는 온도영역을 ductility-dip temperature range(DTR)이라 부른다. 특히, 니켈기반 합금 에서는 두 종류의 균열이 모두 발생하므로 이에 관한 이해가 중요하다.

응고균열에 관련된 이론은 1940 년대부터 이루어졌으 며 Table 1에 정리된 바와 같이 수축취성이론, 변형이 론, Borland이론, 강도이론 등을 기반으로 계속 발전하 고 있다 ${ }^{3-9)}$. 고액공존영역인 mushy-zone이 응고하면 서, 주상형 수지조직이 발달하고 수지상 돌기 사이에 액 상의 필름이 응고되는 과정에서 응고 균열이 형성된다.

특히, 합금원소나 불순물원소들이 주로 고액계면에 편 석하여 응고종료온도를 저하시킨다. 따라서, 고상의 성 장과 액상의 변화 및 움직임, 그리고 야금학적 조성에 의한 응고온도 등에 관한 이해를 기반으로 한 이론적인 모델링 발전이 이루어지고 있다. 또한, 실험적으로 균 열에 민감한 온도영역과 비교 및 분석을 통해 평가되고

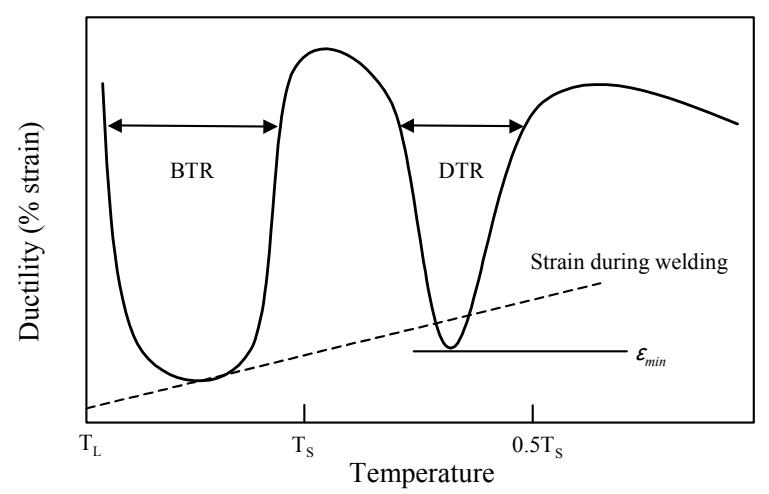

Fig. 1 Ductility curve of metal with temperature range of formation of hot cracking ${ }^{2}$
있다.

액화균열의 발생기구도 응고균열과 동일하며, 다만, 용융선 밖의 열영향부(heat affected zone, HAZ) 측 으로 성장하는 것을 특징으로 한다. 액상이 HAZ의 결 정립과 높은 접촉각(wetting angle) 혹은 작은 이면각 (dihedral angle)을 가지는 경우 결정립 입계로 액상 이 침투하여 조직이 취화 된다. 혹은, HAZ의 합금원소 및 불순물원소의 농도가 입계에 집중된 경우에 임계액 화온도가 낮아지고 $\mathrm{HAZ}$ 의 국부적인 온도가 이를 넘어 서는 경우에 입계만 액화되어 취화될 수 있다.

연성저하균열의 경우 액상선 $\left(\mathrm{T}_{\mathrm{L}}\right)$ 이하의 온도에서 발 생하기 때문에 액상이 관여하지 않는다. 따라서, 고상의 결정립 사이에서 발생하는 균열(intergranular cracking)으로도 불리고 있으며, 일반적으로 $\mathrm{Ni}$ 관련 합금의 경우 Fig. 1 과 같이 $0.5 \mathrm{~T}_{\mathrm{L}} \sim 0.8 \mathrm{~T}_{\mathrm{L}}$ 의 영역에서 재료의 $\mathrm{DTR}$ 이 존재하는 것으로 알려져 있다. 용접부 균열은 용접 중에 발생하거나 누적된 변형이 균열이 발생하기 시작하는 최소 임계 응력 $\left(\varepsilon_{\min }\right)$ 을 초과할 경우에 발생한 다고 볼 수 있다. Lippold에 의한 분류에 의하면 편석 균열보다 상대적으로 낮은 온도 범위에서 발생하는 연 성저하균열, 재열균열(reheat cracking), 변형노화균 열(strain-age cracking) 등을 새로운 카테고리로서 warm cracking이라고 지칭하기도 한다 ${ }^{10)}$.

이처럼 $\mathrm{Ni}$ 합금은 고온재료로서 다양한 분야에서 응용 되고 있으나, 용접시에 생기는 응력 및 변형에 의하여 다양한 고온균열이 발생한다. 이러한 균열은 용접부 특 성을 저하시키고 보수로 인한 경제적인 비용이 추가되 어 생산성이 떨어진다. 따라서, 이를 미리 예측하고 제 어할 수 있는 다양한 용접테스트 방법 및 지표들이 연 구되고 있으며, 야금학적으로 균열을 제어하기 위한 연 구들이 최근까지 계속 이어지고 있다. 이 논문에서는 균열을 시험하고 평가하여 야금학적으로 개선하는 연구 들의 동향을 기술하였다.

Table 1 Proposed hot cracking theory or index of cracking susceptibility ${ }^{3-9)}$

\begin{tabular}{|c|l|l|}
\hline Author(s) & Year & \multicolumn{1}{c|}{ Cracking theory or index } \\
\hline Bochvar & 1947 & The shrinkage-brittleness theory \\
\hline Pellini & 1952 & The strain theory \\
\hline Borland & 1960 & The generalized theory of super solidus cracking \\
\hline Prokhorov & 1962 & The technological strength theory Thermomechanical factor $(\mathrm{d} \varepsilon / \mathrm{dT})$ \\
\hline Feurer & 1976 & Liquid feeding (Volumetric shrinkage $>$ Volumetric feeding) \\
\hline $\begin{array}{c}\text { Matsyda } \\
\text { Coniglio and Cross }\end{array}$ & 1979 & Critical strain rate \\
\hline $\begin{array}{c}\text { Rappaz, Drezet and } \\
\text { Gremaud (RDG) }\end{array}$ & 1999 & Uniaxial tensile deformation $($ Columnar dendrite) and shirinkage feeding \\
\hline Kou & 2015 & Maximum stiffness ldT $/ \mathrm{d}\left(\mathrm{f}_{\mathrm{s}}\right)^{1 / 2} 1$ at near $\mathrm{f}_{\mathrm{s}}=1\left(\mathrm{f}_{\mathrm{s}}:\right.$ solidification fraction) \\
\hline
\end{tabular}




\section{2. 본 론}

\section{1 고온균열 시험}

\subsection{1 고온균열 시험법}

고온균열은 제품의 기능 및 안전을 위해서 생산부터 유지 및 보수까지 필수적으로 제어해야 한다. 고온균열 형성을 관리하기 위하여 국제 수준에서 많은 수의 다양 한 시험법들이 개발되어 왔는데, 이는 용접재료 및 용 접 공정 변수에 따른 용접 품질을 경제적으로 평가하고 새로운 용접재료를 개발하는데 필요하다.

일반적으로 고온균열 시험 방법은 Fig. 2와 같이 크 게 자기구속시험과 외부 변형에 의한 시험으로 분류된 다. 두 방법 모두 용융 풀 근처에서 용접도중에 발생하 는 열/기계적인 응력 및 변형에 의해서 발생하는 고온 균열의 시작 및 전파를 재현하려는 목적과 원리는 비슷 하다. 물론 이러한 시험방법들은 실제 용접에서 응고 균열을 야기하는 열/기계적 조건을 완전히 반영하지는 못한다 ${ }^{11)}$. Goodwin에 의한 보고에 의하면 ${ }^{12)} 1990$ 년 대에 이미 140 개 이상의 고온균열 시험법들이 있었으 며 이중에 95 개는 자기구속 시험이었고 45 개는 외부 변형에 의한 시험들이었다. 지금까지도 균열시험들이 개발 및 발전되었지만 Fig. 2에 제시된 대표적인 시험 법들을 근간으로 하고 있다.

자기구속시험의 경우 용접 전에 시험편의 크기와 기 하학적 모양 또는 용접패스의 모양이나 길이에 따라 재 료에 걸리는 응력 및 변형이 결정된다. 자기구속 고온 균열 시험의 장점은 특별한 시험 장비들이 필요하지 않 고 간단하게 실험 구현이 가능하다. 그러나, 균열의 형 성 유/무, 균열의 길이 등을 분석하여 재료들의 균열감 수성의 경향은 비교가능하나 정량적인 값을 신뢰하기는 어렵다.
외부적인 변형에 의해 고온균열을 평가하는 시험들은 제어할 수 있는 변수들의 변화폭이 넓고 정밀해지고 있 다. 균열이 시작되는 최소 임계 응력, 총 균열 길이(total crack length, TCL)이나 포화된 최대균열길이(maximum crack length, MCL) 등을 정량화하여 평가한다. 또 한, 용접속도 $(\mathrm{V})$ 와 냉각속도(cooling rate)를 이용하여 아래의 식처럼 균열길이를 통해 균열에 민감한 응고균열 온도범위(solidification cracking temperature range, $\mathrm{SCTR)를} \mathrm{실험적으로} \mathrm{구할} \mathrm{수} \mathrm{있다.}$

$$
\text { SCTR }=[\text { Cooling tate }] \times[\mathrm{MCD} / \mathrm{V}]
$$

균열시험법과 함께 DIC(Digital Image Correlation) 기술을 이용하여 직접적인 균열의 형성 및 변형을 측정 할 수 있다. 조명 및 필터링 기술을 이용하여 직접적으 로 관찰할 수 있으며, in-situ SEM을 통한 고배율 관 찰도 보고된다 ${ }^{13)}$. 이러한 기술들은 균열 형성 메커니즘 을 직접적으로 이해하는데 도움을 주고 있다.

\subsubsection{Ni-Cr-Fe 합금의 고온균열시험}

Fig. 3에서는 이 논문에서 다뤄질 합금들을 삼원계 상태도에 나타낸 그림이다 ${ }^{14)}$. 고용강화형 $\mathrm{Ni}-\mathrm{Cr}-\mathrm{Fe}$ 계 합금(alloy 600, alloy 690)을 기준으로 상대적으로 $\mathrm{Fe}$ 함량이 높은 alloy 800 과 alloy 825 를 포함하였 다. 추가적으로 $\mathrm{Mo}$ 가 첨가된 $\mathrm{Ni}-\mathrm{Cr}-\mathrm{Fe}-\mathrm{Mo}$ (alloy 625, Hastelloy X) 및 $\mathrm{Ni}-\mathrm{Cr}-\mathrm{Mo}($ alloy 52)계 합금 과 석출강화 원소 $\mathrm{Nb}, \mathrm{Ta}$ 등을 첨가한 대표적인 석출 강화형 합금 alloy 718 을 비교하여 다루었다.

Fig. 4(a)는 alloy 690 계열의 합금을, spot-varestraint test를 이용하여 균열을 의도적으로 발생시킨 시편이며, Fig. 4(b)는 이를 도식화했다. 응고균열과 액화균열은 용융선을 기준으로 구분되며, 연성저하균열

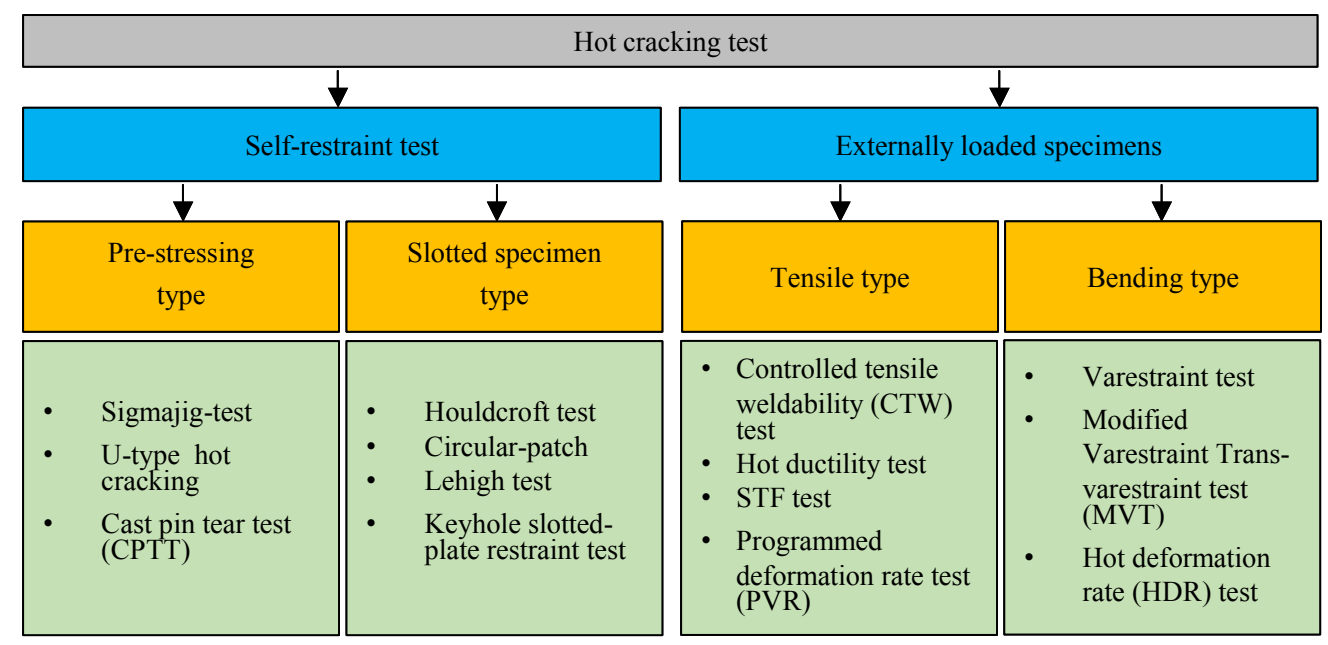

Fig. 2 Flowchart showing the classification of hot cracking measurement method ${ }^{11)}$ 
과 액화균열은 $\mathrm{HAZ}$ 에 위치하여 겹치는 경우가 있으나, Fig. 4(c)-(d)와 같이 파단면을 통해서 구분할 수 있 다. Fig. 4(c)와 같이 파단면에 액상이 흔적이 있으면 액상 필름이 $\mathrm{HAZ}$ 로 침투하여 액화균열을 형성한 경우 이고, Fig. $4(\mathrm{~d})$ 의 파단면은 고상의 결정립 사이에서 발생한 것이다 ${ }^{15)}$. Varestraint 시험의 경우 모든 고온 균열의 민감도 평가가 가능하나 통상적으로 spot-varestraint 시험의 경우 아크를 한곳에 충분히 집중시켜 서 HAZ에 생기는 액화균열과 연성저하균열을 보기에 적합하고 trans-varestraint는 비드 내 응고균열을 보 기에 용이하다.

Fink에 의한 연구에 따르면 ${ }^{16)}$ 다양한 종류의 $\mathrm{Ni}$ 합 금들의 균열감수성을 PVR 시험을 통해 비교하였다. 이

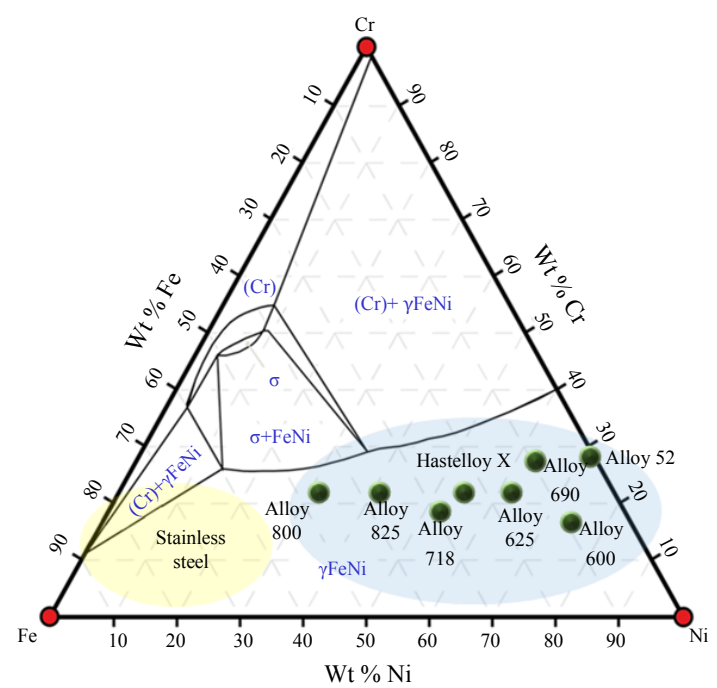

Fig. $3 \mathrm{Ni}-\mathrm{Cr}-\mathrm{Fe}$ Ternary equilibrium phase diagram at $800{ }^{\circ} \mathrm{C}$ and Ni-Cr-Fe alloys and the target alloys (blue colored area) $^{13)}$

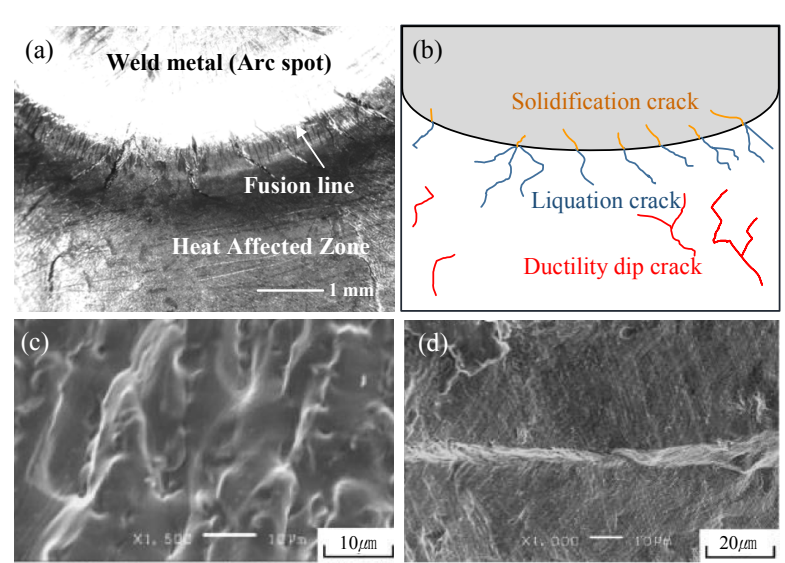

Fig. 4 (a) Macro-structures showing cracks in spot-varestraint test for alloy 690 and (b) its schematic diagram showing types of cracks. Microstructures of (c) HAZ liquation cracking surface and (d) Ductilitydip cracking surface ${ }^{15)}$
시험법은 Prokhorov의 이론에 기반하여 개발되었으며 Fig. 5(a)와 같이 $\mathrm{v}_{\text {cr }}$ (critical tension speed)은 처음 균열이 발생한 임계 변형속도를 나타낸다. $V_{\mathrm{cr}}$ 은 Prokhorov의 이론에서 언급된 임계변형율과 직접적인 관계 가 있는 균열감수성 평가지표이다. Fig. 5(b)에 alloy 59 , alloy $600 \mathrm{H}$, alloy 625 , alloy $800 \mathrm{H}$ 에 대해서 평 가한 결과를 나타내었다. Alloy 59가 균열저항성이 가 장 우수했고 alloy $600 \mathrm{H}$ 가 가장 균열에 민감했으며, 합금 종류에 따라서 민감한 균열 종류와 $\mathrm{V}_{\mathrm{cr}}$ 또한 상당 히 상이한 것을 볼 수 있다.

$\mathrm{Ni}-\mathrm{Cr}-\mathrm{Fe}-\mathrm{Mo}$ 계 합금인 Hastelloy X와 Alloy 625 의 경우, Scheil-Gulliver 시뮬레이션과 varestraint test 결과 모두 편석균열 $(\mathrm{LC}, \mathrm{SC})$ 에 민감한 것으로 잘 일치하였지만, 실제 용접에서 alloy 625는 Hastelloy $\mathrm{X}$ 에 비하여 균열이 상당히 적다. 이는, alloy 625 의 경우 실제용접상황과 비슷한 적당한 응력 하에서는 백 필링(backfilling)이 발생하여 균열이 회복되기 때문이 다 ${ }^{17)}$. 따라서, 높은 응력 하에 포화된 $\mathrm{MCD}$ 으로부터 계산된 SCTR보다는 균열이 발생하기 시작하는 최소 임계 응력이 더 유용하다. 따라서, 이렇게 백필링이 발 생하는 시스템의 경우 실질적인 용접균열을 측정하고 예 측하기 위한 추가적인 연구가 필요할 것으로 사료된다.

Alloy 600 계열 내에서도 alloy $600 \mathrm{H}$ 와 같이 열처 리가 추가적으로 진행된 경우에 alloy 600보다 평균 결정립 크기가 커지고 $\mathrm{MC}$ 및 $\mathrm{M}_{23} \mathrm{C}_{6}$ 같은 탄화물이 석

(a)

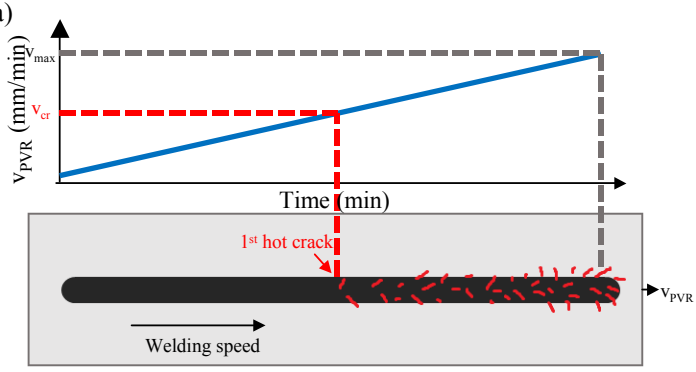

(b)

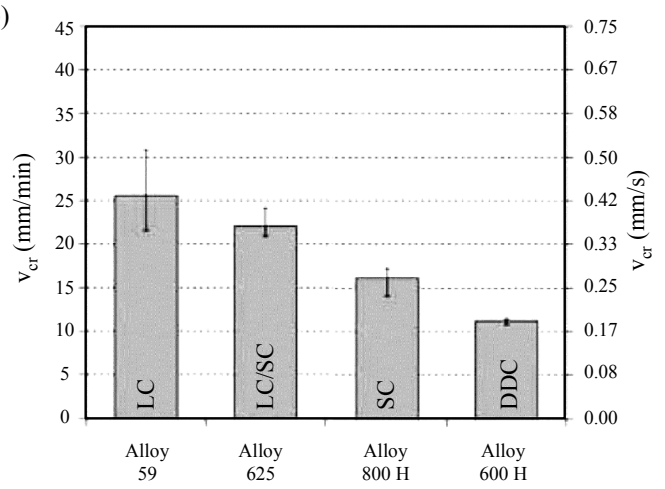

Fig. 5 (a) schematic diagram of PVR test and (b) ranking of hot cracking resistance of $\mathrm{Ni}-\mathrm{Cr}-\mathrm{Fe}$ alloys via PVR test ${ }^{16)}$ 

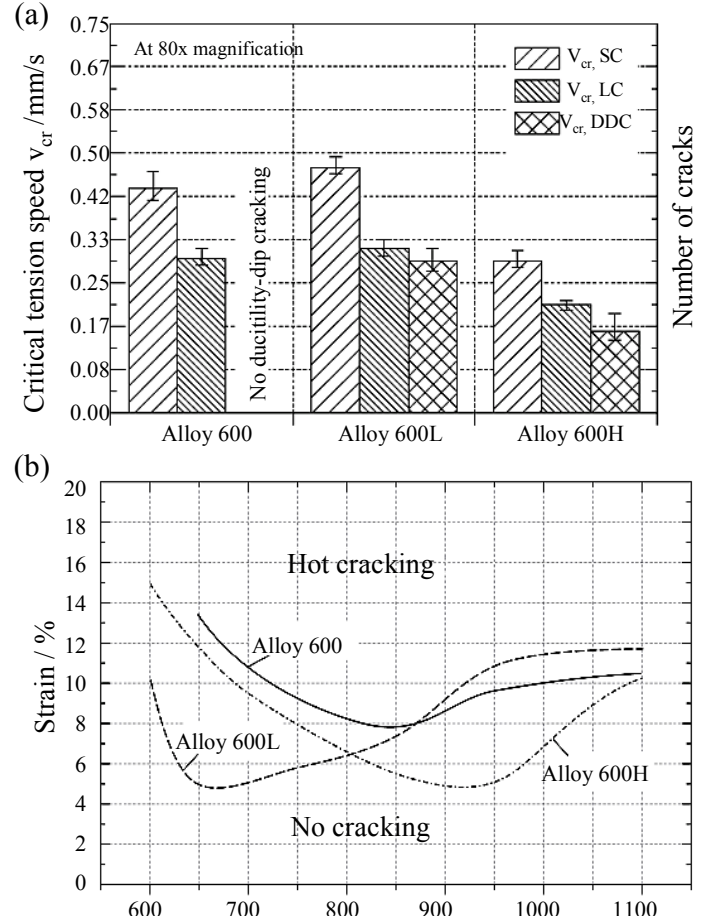

Fig. 6 (a) Ranking of alloy 600 type base metals for cracking susceptibility based on PVR test and (b) its strain-temperature curve based on STF test ${ }^{19)}$

출하여 모든 균열의 감수성이 증대된 것을 볼 수 있다 (Fig. 6(a) $)^{18)}$. 또한, alloy 600L과 alloy 600은 탄 소함량이 각각 $0.003 \mathrm{wt} \%$ 와 $0.07 \mathrm{wt} . \%$ 으로, alloy 600L에서는 연성저하균열 감수성이 alloy 600보다 상 당히 증가하였다. Fig. 6(b)의 Gleeble®기반 인장형 시험인 strain-to-fracture(STF)를 통해 DTR을 구 하여 $10 \%$ 변형을 기준으로 DTR을 평가한 결과 alloy 600 은 $200 \mathrm{~K}$, alloy 600L은 $300 \mathrm{~K}$, alloy $600 \mathrm{H}$ 는 $400 \mathrm{~K}$ 로 PVR시험(Fig. 6(a))의 균열감수성 결과와 유사했다 ${ }^{19)}$. 이처럼 조성 차이가 큰 다른 $\mathrm{Ni}-\mathrm{Cr}-\mathrm{Fe}$ 합금에서 뿐만 아니라 열처리 및 탄소함량 등 소량의 첨가물에 대해서도 균열감수성의 차이가 큰 것을 알 수 있다.

한편, Alloy 600는 다양한 부식 손상이 보고된 바 있다. 따라서, Cr함량이 많은 alloy 690로 대체되고 있는 추세 이나 alloy 690 계열 용가재( $\mathrm{NiCrFe}^{-7}$ 혹은 FM52 등으로도 사용)는 연성저하균열에 매우 취약하기 때문 에, alloy 690계열에서 연성저하균열을 향상시키기 위 한 야금학적인 개선 및 균열 메커니즘에 관한 연구가 많 이 이루어지고 있다.

\section{2 고온 균열에 미치는 합금원소의 영향}

\subsubsection{P와 $\mathrm{S}$ 의 영향}

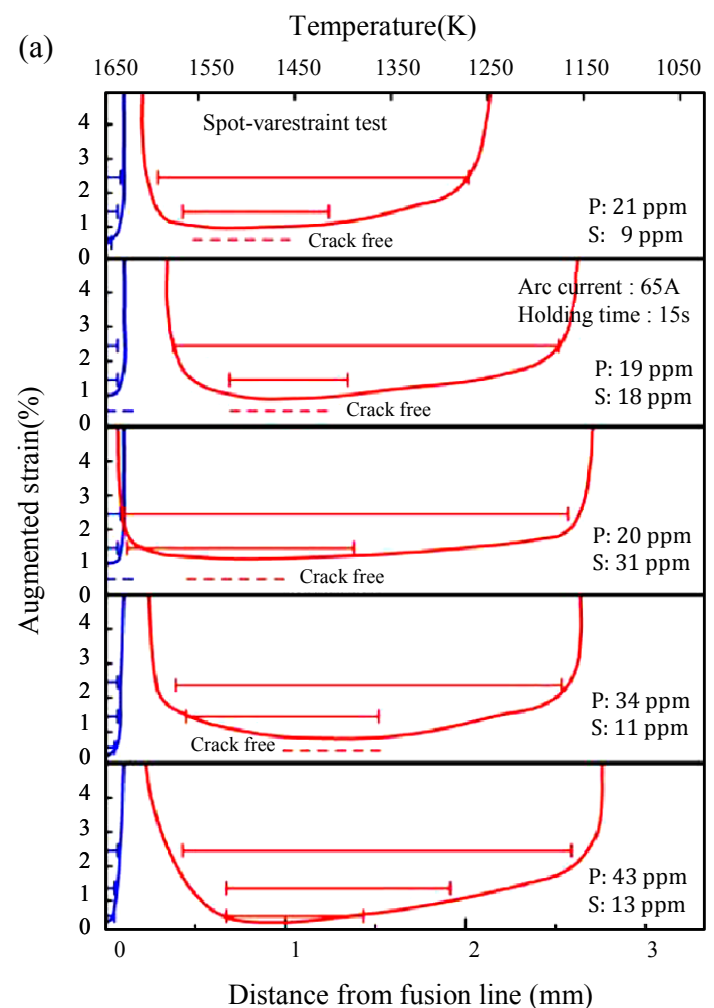

(b)

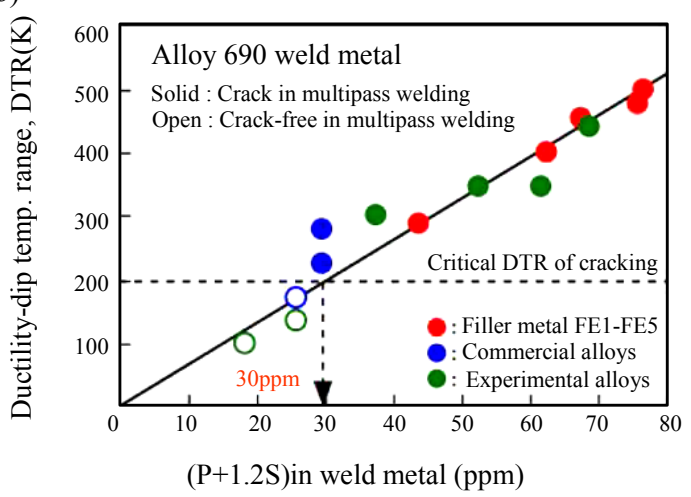

Fig. 7 (a) BTR and DTR with various $\mathrm{P}$ and S contents via spot-varestraint test (b) relationship between DTR and $(\mathrm{P}+1.2 \mathrm{~S})$ in weld metal ${ }^{20)}$

용가재의 $\mathrm{P}$ 또는 $\mathrm{S}$ 가 결정립 계면에 편석되어 연성저 하균열 감수성을 향상시킨다는 보고가 많다. Fig. 7(a) 와 같이 다양한 $\mathrm{P}$ 와 $\mathrm{S}$ 함량을 가진 Alloy 690계 용가 재들을 이용하여 spot-varestraint 시험을 이용하여 $\mathrm{BTR}$ 과 DTR을 실험적으로 도출하였다. BTR영역은 P 와 $\mathrm{S}$ 의 함량에 따라서 큰 변화가 없었지만, DTR의 경 우 $\mathrm{P}$ 와 $\mathrm{S}$ 의 함량이 많을수록 $\varepsilon_{\min }$ 및 온도범위가 증가하 는 경향을 나타내었다. 다층패스 용접을 통해 DTR과 $\mathrm{P}$ 와 $\mathrm{S}$ 함량의 영향을 분석한 결과 $(\mathrm{P}+1.2 \mathrm{~S})$ 의 값이 $\mathrm{DTR}$ 온도 범위와 선형적으로 비례하였고, 균열을 제어 하기 위해서 이 값이 $30 \mathrm{ppm}$ 이하로 제어되어야 한다 20). (Fig. 7(b)) 
기존에 연구되던 varestraint test는 대부분 가스 텅스텐 아크 용접으로 이루어졌으나, Ogura에 의한 연 구에서는 ${ }^{21)}$ 레이저를 이용한 다층패스 용접을 통해 $\mathrm{P}$ 와 $\mathrm{S}$ 의 함량에 대해서 분석하였다. 다중회귀분석 결과 $(\mathrm{P}+2.42 \mathrm{~S})$ 와 DTR 사이에 선형적인 관계가 있었고 이는 $\mathrm{S}$ 의 함량의 영향이 $\mathrm{P}$ 의 함량에 비하여 2.42 배 크 다는 것을 의미한다. 이는, 레이저 용접은 빠른 가열 및 냉각속도로 인하여 결정립 입계에 편석되는 불순물 원소 및 조직을 변화시켜 균열감수성을 감소시키는 것 으로 사료된다 ${ }^{22,23)}$.

이처럼 $\mathrm{P}$ 에 비하여 $\mathrm{S}$ 의 영향이 균열에 미치는 영향 이 크기 때문에, 균열을 감소시키기 위해서 계면에 존 재하는 $\mathrm{S}$ 의 함량을 줄이는 것이 중요하다. 따라서, 고 융점을 가지고 $\mathrm{S}$ 과 친화력이 좋은 금속원소들을 이용하 여 계면의 $\mathrm{S}$ 를 제어할 수 있으며, 이러한 황화물을 Table 2에 나타내었다.

Saida에 의한 연구에 따르면 alloy 690과 스테인리 스강 $316 \mathrm{~L}$ 의 다층패스 용접에서 희토류 금속인 $\mathrm{La}^{24,25)}$ 와 $\mathrm{Ce}^{26)}$ 원소를 용가재에 첨가하여 연성저하균열을 제 어한 결과를 보고한 바 있다. Table 2와 같이 $\mathrm{La}$ 와 $\mathrm{Ce}$ 의 황화물은 자유에너지가 낮아서 형성되기 쉽고 높 은 융점을 가지기 때문에 위 같은 희토류 원소에 의해 서 계면의 $\mathrm{S}$ 함량이 제어되어 균열감수성을 감소시킬 수 있다 ${ }^{27)}$.

\section{2 .2 기타 합금원소의 영향}

$\mathrm{Ni}-\mathrm{Fe}-\mathrm{Cr}$ 합금에서 금속원소의 첨가에 따라서 새로 형성될 수 있는 상들을 Table 3에 정리하였다. 내화 원소인 주기율표 4 6족의 원소들은 탄소와 친화력이 좋아서 탄화물을 만든다. $\mathrm{Cr}$ 탄화물은 $\mathrm{Cr}_{23} \mathrm{C}_{6}$ 로서 계

Table 2 Various sulfides and its free energy of formation and melting points ${ }^{27)}$

\begin{tabular}{|c|c|c|}
\hline Sulphide & $\begin{array}{c}\text { Free energy of formation, } \\
\text { kcal/mol }\end{array}$ & Melting point, K \\
\hline $\mathrm{Ti}_{2} \mathrm{~S}$ & -22.4 & 1683 \\
\hline $\mathrm{NiS}$ & -26.2 & 1253 \\
\hline $\mathrm{FeS}$ & -28.2 & 1468 \\
\hline $\mathrm{CrS}$ & -41.7 & 1840 \\
\hline $\mathrm{Fe}_{2} \mathrm{~S}$ & -44.7 & 1016 \\
\hline $\mathrm{MnS}$ & -52.0 & 1803 \\
\hline $\mathrm{MoS}_{2}$ & -70.2 & 1458 \\
\hline $\mathrm{MgS}_{\mathrm{Mo}} \mathrm{S}_{3}$ & -86.2 & 2000 \\
\hline $\mathrm{LaS}_{\mathrm{CeS}}$ & -106.0 & 1500 \\
\hline $\mathrm{ZrS}_{2}$ & -114.0 & 2600 \\
\hline
\end{tabular}

Table 3 The phases and their crystal structure typically observed in Ni-Cr-Fe alloys ${ }^{28)}$

\begin{tabular}{|c|c|c|}
\hline Phase & Crystal structure & Typical formula \\
\hline$\gamma$ & $\mathrm{FCC}$ & $\mathrm{Ni}(\mathrm{Cr}, \mathrm{Fe}, \mathrm{Mo})$ \\
\hline$\gamma^{\prime}$ & $\mathrm{FCC}$ & $\mathrm{Ni}_{3}(\mathrm{Al}, \mathrm{Ti})$ \\
\hline$\gamma^{\prime}$ & $\mathrm{BCT}$ & $\mathrm{Ni}_{3} \mathrm{Nb}$ \\
\hline$\delta$ & Orthorhombic & $\mathrm{Ni}_{3} \mathrm{Nb}$ \\
\hline$\sigma$ & Tetragonal & $(\mathrm{Cr}, \mathrm{Mo})_{\mathrm{x}}(\mathrm{Ni}, \mathrm{Co})_{\mathrm{y}}$ \\
\hline Laves phase & Cubic $/$ Hexagonal & $(\mathrm{Ni}, \mathrm{Fe}, \mathrm{Cr})_{2}(\mathrm{Nb}, \mathrm{Ti}, \mathrm{Mo})$ \\
\hline $\mathrm{MC}^{\mathrm{N}}$ & FCC & $(\mathrm{Ti}, \mathrm{Nb}) \mathrm{C}$ \\
\hline $\mathrm{M}_{23} \mathrm{C}_{6}$ & FCC & $(\mathrm{Cr}, \mathrm{Fe}, \mathrm{W}, \mathrm{Mo})_{23} \mathrm{C}_{6}$ \\
\hline $\mathrm{M}_{6} \mathrm{C}$ & Cubic & $\mathrm{Fe}_{3} \mathrm{Mo}_{3} \mathrm{C}$ \\
\hline
\end{tabular}

면에 부분적으로 정합을 형성하기 때문에 부정합 계면 에 지협적인 응력이 집중되어 연성저하균열이 형성되기 쉽다 ${ }^{29)}$. 따라서, 고온에서 탄소를 소모할 수 있는 $\mathrm{MC}$ 형 탄화물을 만들거나 $\mathrm{M}_{23} \mathrm{C}_{6}$ 형 탄화물의 형성온도를 낮춰야 한다.

특히, $\mathrm{B}$ 의 첨가는 $\mathrm{M}_{23} \mathrm{C}_{6}$ 형 탄화물의 상 안정성 및 석 출속도를 증가시키기 때문에 결정립 사이에 $\mathrm{M}_{23}(\mathrm{C}, \mathrm{B})_{6}$ 석출물의 크기와 길이가 증가시켜 연성저하균열을 증가 시킨다. 또한 새로운 이차상인 $\mathrm{M}_{2} \mathrm{~B}$ 상은 주변 결정립 과 모든 방향에 대해 부정합을 형성하여 균열을 증가시 킨다 ${ }^{30)}$.

$\mathrm{MC}$ 형 탄화물은 응고말기에 계면에서 액상의 필름이 공정반응에 의하여 응고될 때, 결정립 계면에 고정되어 계면을 구불구불하게 만들어 입계 미끄럼(grain boundary sliding, GBS)을 제한하고, 연성저하균열 저항 성이 증가한다 ${ }^{31,32)}$.

$\mathrm{Nb}$ 와 $\mathrm{Ti}$ 가 $\mathrm{MC}$ 형 탄화물을 만들며, $\mathrm{Mo}$ 에 의한 연 구에 따르면 두 원소의 함량의 증가를 통해 균열의 수 와 길이를 모두 감소시켰으며 이는 인장강도와 연신율 을 동시에 향상시켰다 ${ }^{33)}$.

또한, 열역학 기반 소프트웨어를 통하여 평형상태도,
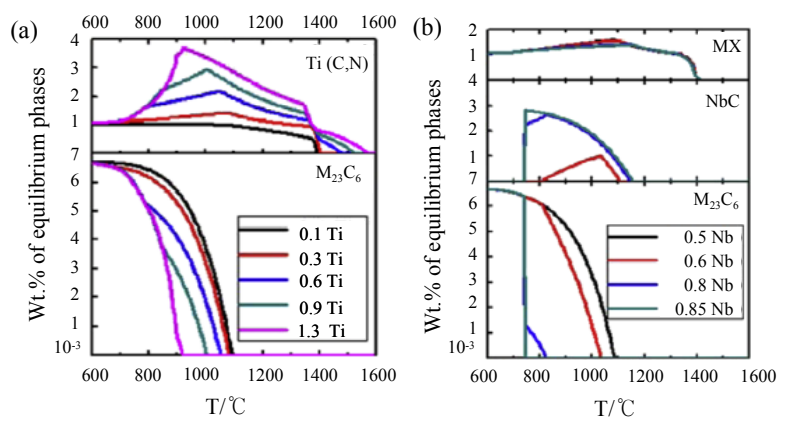

Fig. 8 The influence of (a) $\mathrm{Ti}$ (b) $\mathrm{Nb}$ on the equilibrium phases for alloy $690^{33)}$ 
각각의 평형상 및 분률 등을 계산하여 균열 메커니즘 분 석 및 균열감수성 지표 개발에 도움을 주고 있다. Fig. 8 과 같이 $\mathrm{Ti}, \mathrm{Nb}$ 함량에 따른 평형상태에 존재하는 상 들의 함량을 계산하였다. $\mathrm{Ti}$ 의 경우 $\mathrm{M}_{23} \mathrm{C}_{6}$ 의 형성온도 를 $920{ }^{\circ} \mathrm{C}$ 까지 낮출 수 있었지만, $\mathrm{Nb}$ 의 경우에는 730 ${ }^{\circ} \mathrm{C}$ 까지 낮췄다. 따라서, $\mathrm{Nb}$ 가 $\mathrm{Ti}$ 보다 $\mathrm{M}_{23} \mathrm{C}_{6}$ 상의 형성 을 억제하는데 있어서 더 효과적임을 알 수 있다 ${ }^{33)}$.

$\mathrm{Ti}$ 는 $\mathrm{TiC}$ 형성 외에도 산화물을 형성하여 산화를 방 지하기 때문에 기공을 감소시키는 장점이 있다 ${ }^{31,33)}$. Lee에 의한 연구에서는 ${ }^{34)}$ 분말을 이용하여 alloy 690에 $\mathrm{Ti}$ 의 함량을 증가시켰으나, 용융 풀의 유동이 감소하여 슬래그가 떠오르기 어려워져 내부에 산화물이 개재물로 존재했다.

따라서, 연성저하균열 제어 측면에서 $\mathrm{Ti}$ 함량만으로 는 제어가 어려우며 $\mathrm{Nb}$ 를 통해 제어하는 것이 더 효과 적이다 ${ }^{35)}$. 그러나, $3.0 \mathrm{wt} \%$ 이상의 $\mathrm{Nb}$ 을 첨가하면 $\mathrm{Ni}_{3} \mathrm{Nb}$ 같은 $\gamma^{\prime \prime}$ 상과 $\delta$ 상의 형성이 응고균열을 상당히 증 가시킨다는 보고가 있다 ${ }^{36)}$.

의도적으로 $\mathrm{Nb}, \mathrm{Ta}$ 를 다량 함유하여 석출강화시킨 alloy 718 의 경우, 이 합금은 $\mathrm{\gamma}^{\prime \prime}\left(\mathrm{Ni}_{3} \mathrm{Nb}\right)$ 의 석출에 의 해 강화된다. 앞서 다룬 고용체 강화형 합금들에 비해서 연성저하균열이 현저하게 감소하지만, 상대적으로 열영 향부에 존재하는 액화균열이 문제된다. Fig. 9은 alloy 718의 TTT선도(항온변태선도)를 나타낸 것이다 ${ }^{37}$. 시 효온도 및 유지시간에 따라서 강화 상의 종류와 결정립 의 크기가 달라지기 때문에 열처리 조건에 따라서 다양 한 응고상이 출현한다. 또한, 같은 조성에서 결정립 크 기가 작을수록 열영향부의 액화균열이 감소하는 경향이 존재한다. 따라서, 야금학적 변화를 통해 결정립 크기 및 이차상의 변화 등을 측정하고 이를 균열과 관련시키 는 연구가 많이 보고된다. 특히, $\mathrm{Ce}$ 를 첨가하면 결정립 사이의 Laves 상과 $\mathrm{S}$ 의 편석이 감소할뿐만 아니라 결

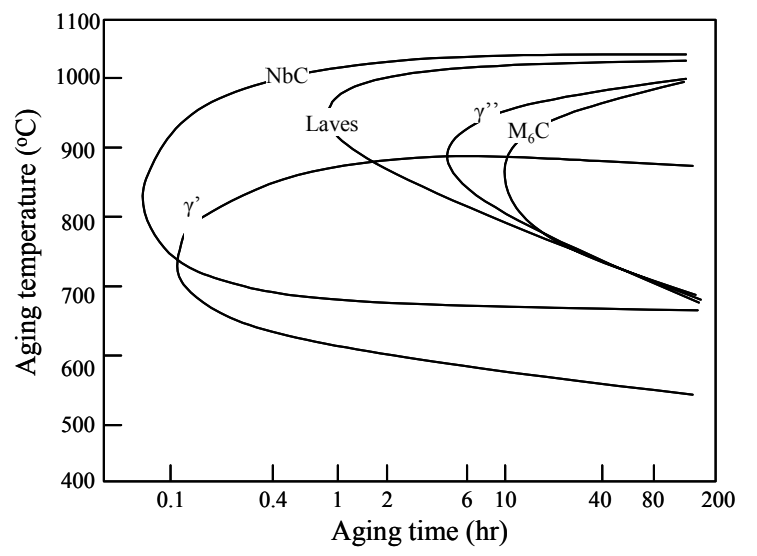

Fig. 9 Time-temperature-transformation diagram for the alloy 718 , which is solution-annealed at $1150{ }^{\circ} \mathrm{C}^{37)}$

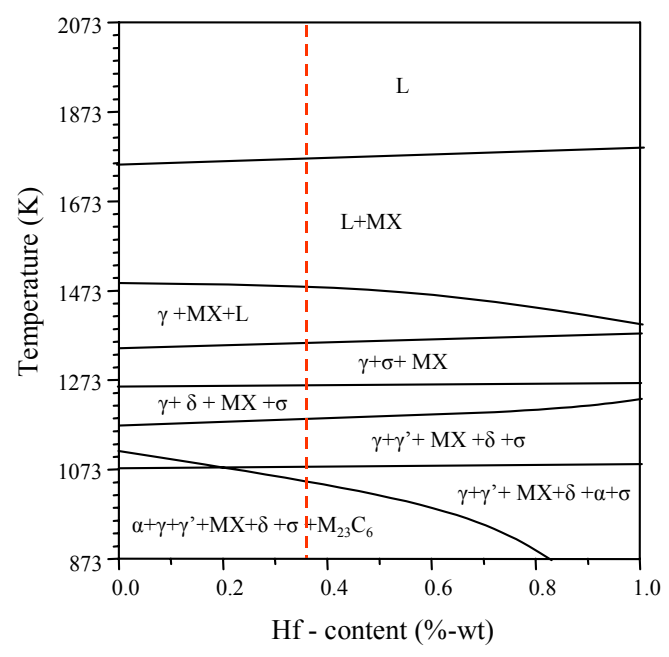

Fig. 10 Binary diagrams between alloy 690 and additions of Hafnium as a function of temperature ${ }^{40)}$

정립 크기 또한 감소하여 액화균열이 감소한다 ${ }^{38)}$.

$\mathrm{Mo}$ 를 통하여 $\mathrm{Nb}$ 를 대체하려는 연구도 진행되었으 나, $\mathrm{Nb}$ 와 $\mathrm{Mo}$ 같은 경우 $\gamma$ 상의 고용강화로 강도 증가에 기여하나 많은 양을 첨가하거나 탄소가 상대적으로 적 은 곳에서 $\mathrm{Ni}_{2}(\mathrm{Nb}, \mathrm{Mo})$ 같은 Laves 상을 만든다 ${ }^{39)}$. Laves와 $\mathrm{\gamma}$ 상 사이의 계면이 많아지면 응고균열 감수성 이 높아지며 충격인성을 저하되어 변형 시, 상 주변으 로 기공이 집중되고 파단까지 이어진다.

$\mathrm{Nb}$ 를 대체하려는 또 다른 후보군으로 $\mathrm{Hf}, \mathrm{Ta}$ 같은 원소들을 사용한 보고가 있다 ${ }^{40,41)} \mathrm{Hf}$ 의 경우 일정량 이상을 첨가하면 $\mathrm{M}_{23} \mathrm{C}_{6}$ 를 완벽하게 제어할 수 있으며 (Fig. 10), $\mathrm{Ta} \mathrm{Mo}$ 를 같이 첨가하는 경우에 첨가 함량 에 따라서 응고말기의 공정 반응이 바뀌며, Laves 상 의 제어가 가능하다고 보고된 바 있다.

\section{3. 결 론}

고온특성이 우수한 $\mathrm{Ni}-\mathrm{Fe}-\mathrm{Cr}$ 재료의 응고균열, 액화 균열, 연성저하균열 등의 각 균열들이 발생하는 원리와 분석법들에 대해서 살펴보았다. 또한, 최근까지 $\mathrm{Ni}-\mathrm{Fe}-\mathrm{Cr}$ 각 합금에서의 이슈와 함께 야금학적인 변화가 균열에 미치는 영향에 대해서 정리하였다.

1) 고온균열시험은 분석하고자 하는 균열의 종류, 분 석 정밀도, 재현성 등에 따라서 여러 종류의 균열 시험 들 및 열역학 시뮬레이션 등이 상호보완적으로 이용되 고 있다.

2) Alloy 625같이 백필링이 발생하는 경우, 시뮬레 이션 결과와 균열시험이 일치하더라도 실제 용접부의 균열감수성을 경향과 일치하지 않는 경우가 있다.

3) 따라서, 실제 용접을 직접 관찰하는 카메라, SEM 등의 in-situ 측정기술을 통한 연구 또한 이루어지고 
있다.

4) 기술의 발전과 함께 향상된 소재가 요구되며 야금 학적 변화를 통해 이를 해결하려는 시도가 연구되고 있다.

5) 용접 공정에 따라 균열감수성이 다르며, 주로 아 크 용접으로 이루어지던 균열 분석이 레이저 용접 등 다양한 용접 공정을 통해 이루어지고 있다.

6) 응고경로 및 응고상의 종류가 열처리 온도와 시간 그리고 냉각속도 등에 의해서 복잡하게 변하고 이에 따 라 균열감수성도 변하기 때문에 이와 관련된 연구가 지 속되고 있다.

7) 또한, $\mathrm{Ni}-\mathrm{Cr}-\mathrm{Fe}$ 합금에서 $\mathrm{Nb}$ 를 대체하기 위한 새로운 후보군으로 다양한 탄화물을 만드는 내화원소들 이 검토되고 있다.

이와 같이 균열감수성에 미치는 야금학적 영향이 중 요하며, 변화에 따라서 실제 용접을 효과적으로 재현할 수 있는 시험법 및 균열감수성 지표들이 필요하다. 이 를 통해 균열을 저감하며 새로운 용접재료 설계에 도움 을 줄 것으로 사료된다.

\section{Reference}

1. H.-C. Yoo, Recent study of materials and welding methods for nuclear power plant, J. of Welding and Joining, 33(1) (2015), 14-23 (in Korean)

2. J. C. Lippold, Elevated Temperature, Solid-State Cracking in Welds, in Cracking Phenomena in Welds IV, Springer, (2016), 229-265

3. S. Kou, A Simple Index for Predicting the Susceptibility to Solidification Cracking, Welding Journal, 94(12) (2015), 374s-388s

4. S. Kou, A criterion for cracking during solidification, Acta Materialia, 88 (2015), 366-374

5. N. Coniglio and C. E. Cross, Mechanisms for Solidification Crack Initiation and Growth in Aluminum Welding, Metallurgical and Materials Transactions a-Physical Metallurgy and Materials Science, 40a(11) (2009), 2718-2728

6. M. Rappaz, J. M. Drezet and M. Gremaud, A new hottearing criterion, Metallurgical and Materials Transactions a-Physical Metallurgy and Materials Science, 30(2) (1999), 449-455

7. F. Matsuda, H. Nakagawa, K. Nakada and H. Okada, The VDR cracking test for solidification crack susceptibility on weld metals and its application to aluminum alloys, Trans JWRI, 8 (1979), 85-95

8. U. Feurer, Mathematical Model by the Hot Cracking Tendency of Binary Aluminum Alloys, Giessereiforschung, 28(2) (1976), 75-80

9. N. N. Prokhorov, Resistance to hot tearing of cast metals during solidification, Russian Castings Production, 2(2) (1962), 172-175

10. J. C. Lippold, Recent developments in weldability test- ing for advanced materials, ASM International-Joining of Advanced and Specialty Materials. VII, (2005)

11. T. Kannengiesser and T. Boellinghaus, Hot cracking testsan overview of present technologies and applications, Welding in the World, 58(3) (2014), 397-421

12. G. Goodwin, Test methods for evaluating hot cracking: review and perspective, (Oak Ridge National Lab., TN (USA), 1990)

13. E. A. Torres, F. Montoro, R. D. Righetto and A. J. Ramirez, Development of high-temperature strain instrumentation for in situ SEM evaluation of ductility dip cracking, $J$. Microsc, 254(3) (2014), 157-165

14. D. Feron and R. W. Staehle, Stress Corrosion Cracking of Nickel Based Alloys in Water-cooled Nuclear Reactors: The Coriou Effect, Woodhead Publishing, 2016, 11-18

15. K. Saida, Y. Nomoto, H. Okauchi, H. Ogiwara and K. Nishimoto, Influences of phosphorus and sulphur on ductility dip cracking susceptibility in multipass weld metal of alloy 690, Science and Technology of Welding and Joining, 17(1) (2013), 1-8

16. C. Fink, D. Keil and M. Zinke, Evaluation of Hot Cracking Susceptibility of Nickel-Based Alloys by The PVR Test, Welding in the World, 56(7-8) (2012), $37-43$

17. J. Lippold, J. Sowards, G. Murray, B. Alexandrov and A. Ramirez, Weld solidification cracking in solid-solution strengthened Ni-base filler metals, in Hot Cracking Phenomena in Welds II, Springer, 2008, 147-170

18. C. Fink, An investigation on ductility-dip cracking in the base metal heat-affected zone of wrought nickel base alloys - part I: metallurgical effects and cracking mechanism, Welding in the World, 60(5) (2016), 939950

19. C. Fink, M. Zinke and S. Jüttner, An investigation of ductility-dip cracking in the base metal heat-affected zone of wrought nickel base alloys-part II: correlation of PVR and STF results, Welding in the World, 60(5) (2016), 951-961

20. K. Nishimoto, K. Saida and H. Okauchi, Microcracking in multipass weld metal of alloy 690 Part 1-Microcracking susceptibility in reheated weld metal, Science and Technology of Welding and Joining, 11(4) (2013), 455461

21. Tomo Ogura, Y. Morikawa and K. Saida: Evaluation of Ductility-Dip Cracking Susceptibility in Alloy 690 Laser Multipass Weld Metal by Varestraint Test, in IIW 2017, (Shanghai, 2017)

22. Eun-Joon Chun, Su-Jin Lee, Jeong Suh, Namhyun Kang and K. Saida, Solidification Cracking Behavior in Austenitic Stainless Steel Laser Welds (Part 1) - Evaluation of Solidification Cracking Susceptibility by Laser Beam Welding Varestraint Test, J. of Welding and Joining, 34(5) (2016), 54-60 (in Korean)

23. Minjung Kang, Cheolhee Kim and Young-Min Kim, Evaluation of the Laser Weldability of Inconel $713 \mathrm{C}$ alloy, J. of Welding and Joining, 35(1) (2017), 68-73 
(in Korean)

24. K. Saida, M. Sakamoto and K. Nishimoto, Mechanical Approach for Prediction of Microcracking in Multipass Weld Metal of Ni-Base Alloy 690, Materials Science Forum, 580-582 (2008), 1-4

25. K. Saida, K. Ohta and K. Nishimoto, Microcracking susceptibility in dissimilar multipass welds of alloy 690 to type 316L stainless steel using La added filler metals, Science and Technology of Welding and Joining, 12(7) (2013), 593-603

26. K. Saida, A. Taniguchi, H. Okauchi, H. Ogiwara and K. Nishimoto, Prevention of microcracking in dissimilar multipass welds of alloy 690 to type 316L stainless steel by Ce addition to filler metal, Science and Technology of Welding and Joining, 16(6) (2013), 553-560

27. N. L. Richards and M. C. Chaturvedi, Effect of minor elements on weldability of nickel base superalloys, International Materials Reviews, 45(3) (2000), 109-129

28. J. Andersson: Weldability of precipitation hardening superalloys - influence of microstructure, Chalmers University of Technology, (2011)

29. W. Mo, S. Lu, D. Li and Y. Li, Effects of M 23C6 on the High-Temperature Performance of Ni-Based Welding Material NiCrFe-7, Metallurgical and Materials Transactions A, 45(11) (2014), 5114-5126

30. W. Mo, X. Hu, S. Lu, D. Li and Y. Li, Effects of Boron on the Microstructure, Ductility-dip-cracking, and Tensile Properties for NiCrFe-7 Weld Metal, Journal of Materials Science \& Technology, 31(12) (2015), 1258-1267

31. W. Mo, S. Lu, D. Li and Y. Li, Effects of filler metal composition on the microstructure and mechanical properties for ER NiCrFe-7 multi-pass weldments, Materials Science and Engineering: A, 582 (2013), 326-337

32. K. Saida, K. Bunda, H. Ogiwara and K. Nishimoto, Microcracking susceptibility in dissimilar multipass welds of Ni-base alloy 690 and low-alloy steel, Welding International, 29(9) (2015), 668-680
33. W. Mo, S. Lu, D. Li and Y. Li, Effects of Filler Metal Composition on Inclusions and Inclusion Defects for ER NiCrFe-7 Weldments, Journal of Materials Science \& Technology, 29(5) (2013), 458-466

34. H. T. Lee, S. L. Jeng, C. H. Yen and T. Y. Kuo, Dissimilar welding of nickel-based Alloy 690 to SUS 304L with Ti addition, Journal of Nuclear Materials, 335(1) (2004), 59-69

35. A. J. Ramirez, J. W. Sowards and J. C. Lippold, Improving the ductility-dip cracking resistance of Ni-base alloys, Journal of Materials Processing Technology, 179(1-3) (2006), 212-218

36. K. Yushchenko, V. Savchenko, N. Chervyakov, A. Zvyagintseva and E. Guyot, Comparative hot cracking evaluation of welded joints of alloy 690 using filler metals inconel ${ }^{\circledR} 52$ and 52 MSS, Welding in the World, 55 (9-10) (2011), 28-35

37. A. Lingenfelter, Welding of Inconel alloy 718: A historical overview, Superalloy, 718 (1989), 673-683

38. I. Woo and K. Nishimoto, Metallurgical factors contributing to HAZ cracking susceptibility in cast alloy 718 welds and its improvement by cerium addition, Metals and Materials-Korea, 7(3) (2001), 241-249

39. X. Zhang, D.-Z. Li, Y.-Y. Li and S.-P. Lu, Effect of Nb and Mo on the Microstructure, Mechanical Properties and Ductility-Dip Cracking of Ni-Cr-Fe Weld Metals, Acta Metallurgica Sinica (English Letters), 29(10) (2016), 928-939

40. J. Unfried-Silgado and A. J. Ramirez, Modeling and characterization of as-welded microstructure of solid solution strengthened $\mathrm{Ni}-\mathrm{Cr}-\mathrm{Fe}$ alloys resistant to ductility-dip cracking part I: Numerical modeling, Metals and Materials International, 20(2) (2014), 297-305

41. A. T. Hope and J. C. Lippold, Development and testing of a high-chromium, Ni-based filler metal resistant to ductility dip cracking and solidification cracking, Welding in the World, 61(2) (2017), 325-332 